\title{
On ageing of liquefaction resistance of sand
}

\author{
Ikuo Towhata $^{\text {i) }}$, Shigeru Goto ${ }^{\text {ii)}}$, Yuichi Taguchi ${ }^{i i i)}$, Toshihiko Hayashida ${ }^{\text {iii) }}$, Yuki Shintaku ${ }^{\text {iv) }}$ \\ and Yuki Hamada ${ }^{\text {) }}$
}

\begin{abstract}
i) Professor, Department of Civil Engineering, The University of Tokyo, 7-3-1, Hongo, Bunkyo-ku, Tokyo, 113-8656, Japan.
ii) Researcher, Department of Civil Engineering, The University of Tokyo, 7-3-1, Hongo, Bunkyo-ku, Tokyo, 113-8656, Japan. iii) Researcher, Fudo Tetra Corporation, 7-2, Koamicho, Nihonbashi, Chuo-ku, Tokyo, 103-0016, Japan iv) Former graduate student, The University of Tokyo, 7-3-1, Hongo, Bunkyo-ku, Tokyo, 113-8656, Japan.

v) Master student, Department of Civil Engineering, The University of Tokyo, 7-3-1, Hongo, Bunkyo-ku, Tokyo113-8656, Japan.
\end{abstract}

\begin{abstract}
Mechanical properties of subsoil are frequently subject to temporal change and liquefaction resistance is not an exception. The experiences during the 2011 gigantic earthquake in Japan illustrated that more aged soils did not develop liquefaction. Since this effect of soil age is not explicitly accounted for by existing codes, the authors attempted to interpret cases where subsoil of known age liquefied or not liquefied during past earthquakes. It was found that liquefaction resistance increases after hundreds of years and that the increase of $40 \%$ is reasonably supposed to occur after 400 years. Further study was conducted on the mechanism of ageing in which grain dislocation was focused on.
\end{abstract}

Keywords: liquefaction, ageing, case history, grain fabric

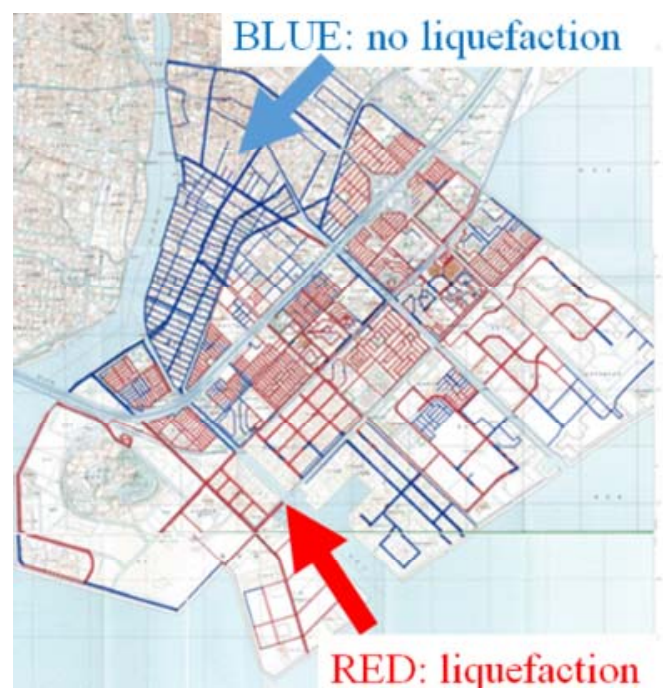

Fig. 1 Contrast in liquefaction occurrence between older alluvial area and younger man-made islands in Urayasu during the 2011 earthquake in east Japan (Joint work of JGS and MLIT, 2012)

\section{INTRODUCTION}

Because subsoil liquefaction is one of the most devastating mechanisms of earthquake damage in urban environment, vulnerability of subsoil to liquefaction has been widely investigated and to date the liquefaction resistance of soil is generally assessed by means of SPT-N together with fines content and other soil properties. The experience during the 2011 gigantic earthquake in eastern Japan, however, revealed that liquefaction vulnerability is lower in older alluvium than in younger artificial ground (Fig. 1). Traditionally, the ignorance of age effects and the conservatism in liquefaction vulnerability assessment have been considered reasonable for design purposes. However, a different situation is emerging in which risk evaluation and hazard mapping are interested in, wherein the conservatism leads to overestimation of liquefaction risk and unnecessary relocation of residences to safer places. Hence, the present study focuses on the age effect so that the liquefaction vulnerability may be more reasonably evaluated.

\section{ON SOIL AGEING}

Soil ageing is a phenomenon in which soil properties vary with time. In particular, the present study focuses on the temporal increase of liquefaction resistance of sand. Similar to the experiences during the 2011 earthquake, liquefaction was concentrated in such younger soils as man-made islands, abandoned river channels and lifeline backfills during such past earthquakes as in Kobe (1995). Moreover, Youd and Hoose (1977) as well as Seed (1979) pointed out the importance of soil age. Nagase et al. (1999) conducted liquefaction tests on undisturbed soil samples to show $30 \%$ increase in liquefaction resistance over 1000 years, and Lewis et al. (2008) revealed significant increase of resistance of undisturbed samples of Miocene age (5 to 23 million years ago). Accordingly, Fig. 2 compares the 
liquefaction resistance of undisturbed (frozen) samples and laboratory-reconstituted samples at the same density to reveal the temporal increase of the resistance over the engineering time period.

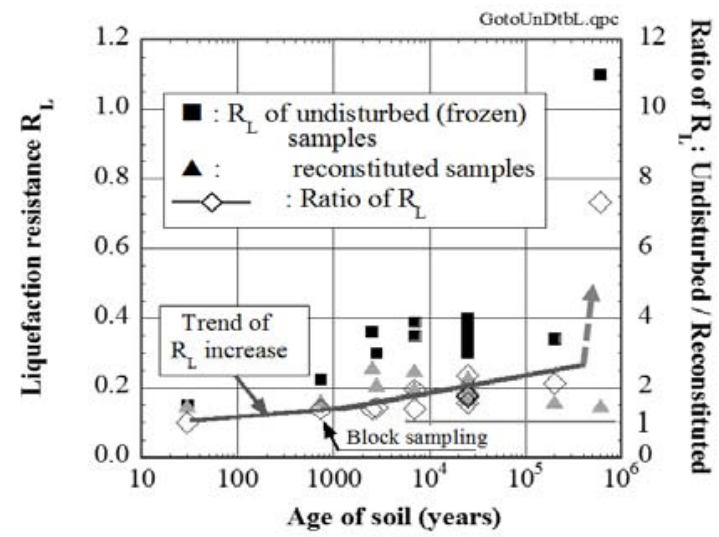

Fig. 2 Ageing increase of liquefaction resistance of sand (data by the authors as well as by Nagase et al., 1999, and Seki et al., 1993.

Furthermore, Matsuo (2004) stated that liquefaction resistance in young man-made islands is systematically lower than that of older alluvium in spite of similar normalized SPT- $\mathrm{N}_{1}$. Because the existing codes rely on experience of liquefaction rather than no occurrence of liquefaction (Table 1), existing practice is possibly more affected by the behavior of younger soils than that of older alluvium.

Table 1 Numbers of data from liquefied and unliquefied conditions as employed in development of design practice

\begin{tabular}{|c|c|c|}
\hline & $\begin{array}{c}\text { Tatsuoka et al } \\
(1980)\end{array}$ & $\begin{array}{c}\text { Matsuo } \\
(2004)\end{array}$ \\
\hline From liquefied sites & 45 & 173 \\
\hline From unliquefied sites & 13 & 54 \\
\hline
\end{tabular}

Soil properties are generally improved with age as exemplified not only by liquefaction resistance but also SPT-N and lithification from soil to rock. Schmertmann (1991) classified this phenomenon into ageing in engineering time and ageing in geological time. Because the present paper addresses the high vulnerability of liquefaction in very recent subsoil having the age of only decades or one hundred years, the engineering ageing is the topic to be discussed. Noteworthy is that SPT blow counts and other sounding resistance increase as well with time and, more interestingly, Baxter and Mitchell (2004) as well as Mitchell and Solymer (1984) and Massarsch and Fellenius (2002) reported that the increase occurs in a time scale of weeks or months only. In line with this, Fig. 3 demonstrates the temporal increase of penetration resistance of subsoil after heavy disturbance by seismic liquefaction or blasting. The original data was obtained by Swedish weight sounding and its increment with time is plotted herein. Obviously the increase is virtually terminated after 100 days or so.

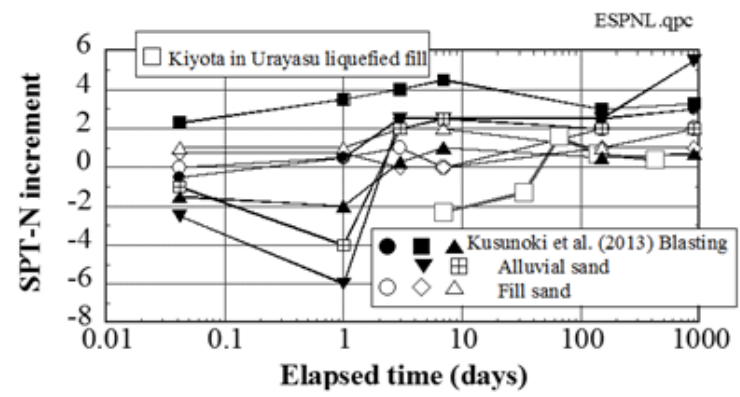

Fig. 3 Temporal change of equivalent SPT-N after heavy disturbance (data by Kiyota's personal communication and Kusunoki et al., 2013).

Because liquefaction practice employs SPT-N value for assessment of soil resistance, the present study focuses on the additional liquefaction resistance that cannot be assessed by the short-time increase of SPT-N value (Fig. 4). The current practice seemingly underestimates the liquefaction resistance of more aged soils because this additional increase is not accounted for.

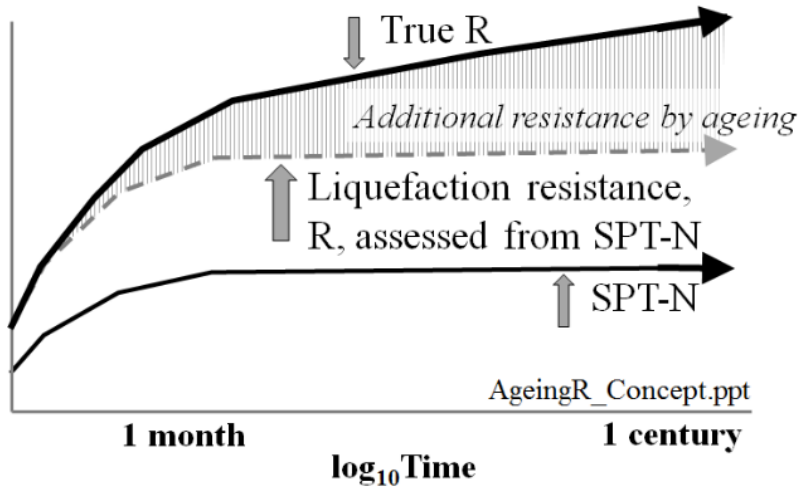

Fig. 4 Schematic relationship among time increases of SPT-N, assessed liquefaction resistance and real resistance

\section{EXPERIENCE DURING THE 2011 GIGANTIC EARTHQUAKE IN EAST JAPAN}

As demonstrated in Fig. 1, liquefaction occurred in recently-constructed man-made islands around the Tokyo Bay. They are all characterized by their young age. Tokyo as a city started its history at the end of the 16 th Century and, since then, many islands have been constructed for urban expansion. Because the history of land construction is well documented in Tokyo (Fig. 5), the age of subsoil can be identified and related with the onset of liquefaction in 2011.

Note again that the present study addresses the additional increase of liquefaction resistance of sand, $\mathrm{R}$, 
that cannot be accounted for by the increase of SPT-N which is completed within a short period of time after land reclamation. First, the study calculates the factor of safety against liquefaction, $\mathrm{F}_{\mathrm{L}}$, by the methods of Highway Bridge Design Code in Japan and examines it against reality. If no liquefaction occurred in 2011 in spite of $F_{L}<1$, the real liquefaction resistance is considered greater. Conversely, if liquefaction did occur in spite of $F_{L}>1$, the resistance should be less. Note that the effect of ageing in SPT-N is taken into account in the SPT-based $\mathrm{F}_{\mathrm{L}}$.

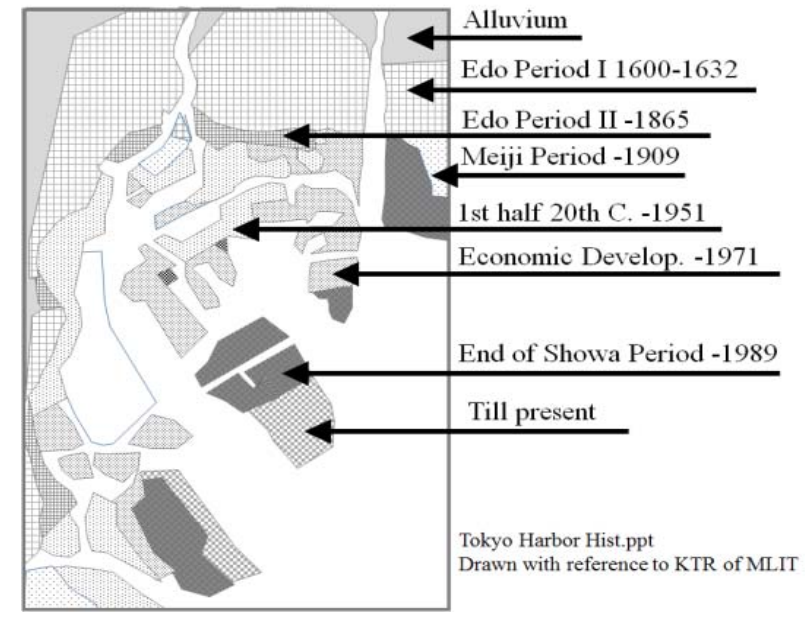

Fig. 5 History of land reclamation in the bay area of Tokyo (Drawn after KTR of MLIT).

Interpretation of $F_{L}$ value is not easy because of a variety of uncertainties such as heterogeneous soil conditions among others. Thus, a special idea of data interpretation was employed as described below in order to detect the boundary $F_{L}$ between liquefaction and no liquefaction. Theoretically this boundary value is 1.0 but it is expected that it decreases as age increases.

1) At sites of liquefaction where sand boiling was reported, the boundary value should be greater than the minimum $F_{L}$ in the entire young soil (Fig.6). This idea is reasonable because, if the boundary were less than this minimal, no liquefaction could have occurred.

2) At sites of no liquefaction, the boundary should be less than the maximum $\mathrm{F}_{\mathrm{L}}$. Otherwise, liquefaction would have occurred over the entire depth (Fig.6).

Although this approach is not perfectly deterministic as meant by such a remark as "should be greater than," it makes it possible to remove unnecessary confusion and obtain a scope about the ageing effect.

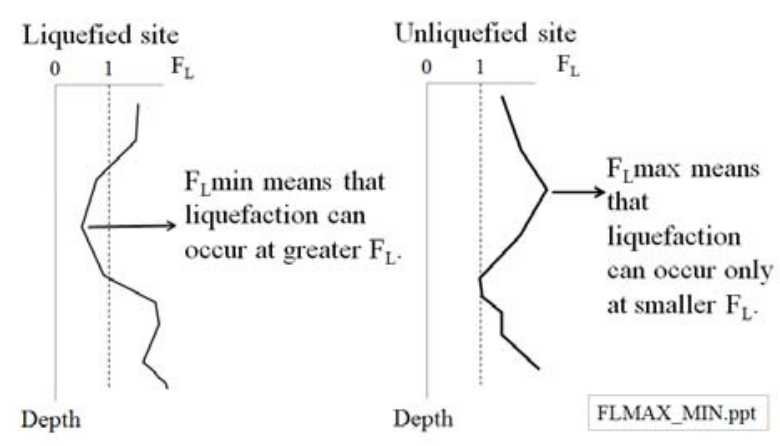

Fig. 6 Use of $F_{L}$, max and $F_{L}$,min in interpretation of calculated $\mathrm{F}_{\mathrm{L}}$ and determining the boundary $\mathrm{F}_{\mathrm{L}}$ between liquefaction and no liquefaction.

\section{BOUNDARY VALUE OF $F_{L}$ BETWEEN LIQUEFACTION AND NO LIQUEFACTION}

Figure 7 plots the calculated $F_{L}$,min and $F_{L}$, max values at sites of liquefaction ( $)$ and no liquefaction $(\bigcirc)$ against time of land construction. The arrows in the figure imply that the boundary value of $F_{L}$ is either greater than or less than the plotted values. The intensity of earthquake acceleration was obtained from the records of nearby K-NET stations where liquefaction did not occur. Thus, Fig. 7 was obtained in which the vertical axis is the calculated $\mathrm{F}_{\mathrm{L}}$ values and the horizontal axis stands for the age of soil (time of land construction). Because the time of construction cannot be determined precisely due to uncertainty of history and a long duration of construction projects, the time was classified into several ranges as well as the natural alluvium that is mostly older than man-made deposits.

The problem in Fig. 7 is that the range of the boundary $F_{L}$ is wide and that it starts from values greater than unity, which is contradictory to the practice. Hence, further improvement was undertaken. First, because the employed design code does not take into account the effects of two-directional (EW and NS) shaking, the obtained $\mathrm{F}_{\mathrm{L}}$ was reduced by multiplying by 0.9 (Ishihara and Yamazaki, 1980). Second, the magnitude $=9$ of the earthquake in 2011 was characterized by a long duration time of shaking and reduced liquefaction resistance. Thus, another multiplication of $\mathrm{Cw}=0.8$, resistance reduced to $80 \%$, was employed. Finally, liquefaction occurred in the area of thick deposit of soft soil where seismic amplification was significant. Because such an effect is not included in the employed K-NET records at unliquefied sites, a third multiplication of 0.75 was made only at sites of liquefaction. This multiplication factor was decided by referring to the Urayasu record of K-NET (PGA = 157 Gal) against other unpublished PGA of about $200 \mathrm{Gal}$ in the liquefaction area. Thus the entire multiplication factors were either $0.9 * 0.8$ or $0.9 * 0.8 * 0.75$. Thus, Fig. 8 was obtained. 


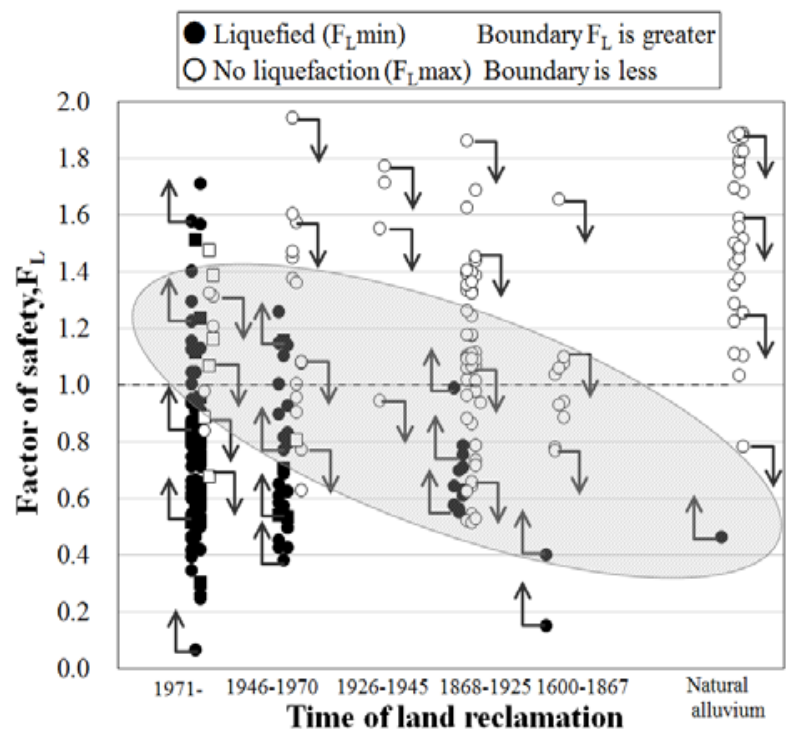

Fig. 7 First outcome on temporal decrease of boundary $F_{L}$ value between liquefaction and no liquefaction (Squares designate soil investigation within 10 years after construction) (Highway Bridge Design Code was employed)

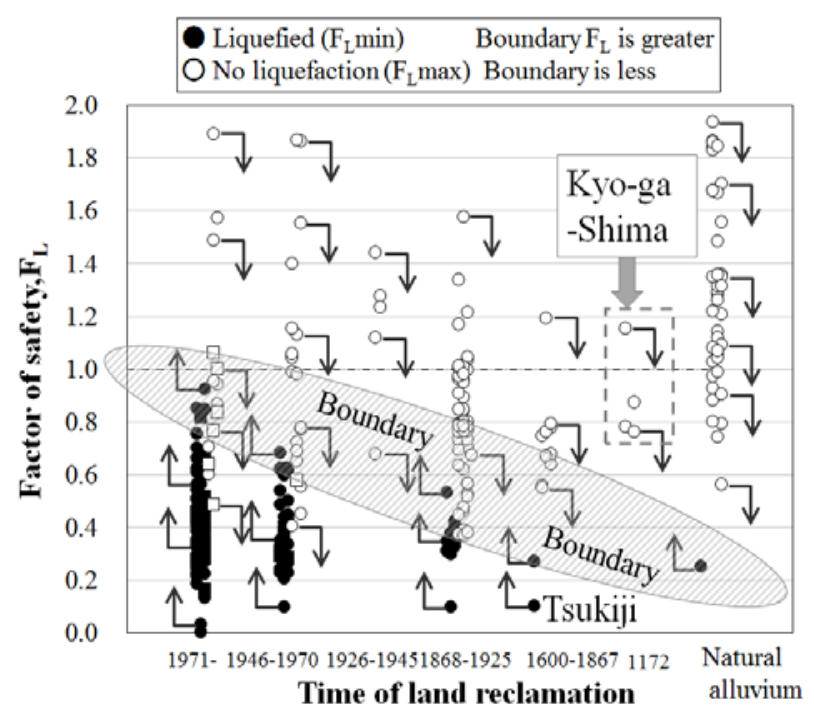

Fig. 8 Improved temporal decrease of boundary $F_{L}$ value between liquefaction and no liquefaction (Squares designate soil investigation within 10 years after construction)

(Highway Bridge Design Code was employed)

No data is available before 1599 in the Tokyo area because of the short history of Tokyo. Note that the age of alluvium is still subject to uncertainty as exemplified by flooding and filling of river channels in recent times. Although the time scale is subject to uncertainty, it is still possible to detect the boundary "range" of $F_{L}$ values between liquefaction and no liquefaction. This boundary range decreases with the age of soil, implying that older soils are less likely to liquefy in spite of smaller $F_{L}$ values. Thus, it is concluded that the liquefaction resistance of aged soil is greater than what is calculated by using SPT-N and other soil data.

\section{STUDY ON OLDER MAN-MADE ISLAND}

The study described above is limited to the Tokyo area where the recorded history is more or less 400 years old. To increase the studied time range, older man-made islands that were subject to strong earthquakes of known intensity had to be studied. The first example of this kind is Tsukiji in Amagasaki near Osaka which was constructed during the second decade of the 17th Century in a shallow sea and liquefied during the 1995 Kobe earthquake. Both borehole data and earthquake motion record are available. The second example is the Kyo-ga-Shima Island of Kobe that was constructed in the present Kobe-Harbor in 1173 by the Heike Government in order to protect the harbor from the South-east wind. The filling material was obtained from nearby mountains. The problem was that the exact location of this island had been lost after many centuries and the present study interpreted an available bore-hole database for its location. Fig. 9 illustrates one of the obtained cross sections of the central part of Kobe where a gravelly deposit near the surface is separated by silty soils from the underlying natural gravelly layer. The silty soil is interpreted as the original sea bed and the surface gravel layer was the Kyo-ga-Shima. JR Takatori motion was recorded near this area and no liquefaction occurred during the Kobe earthquake.

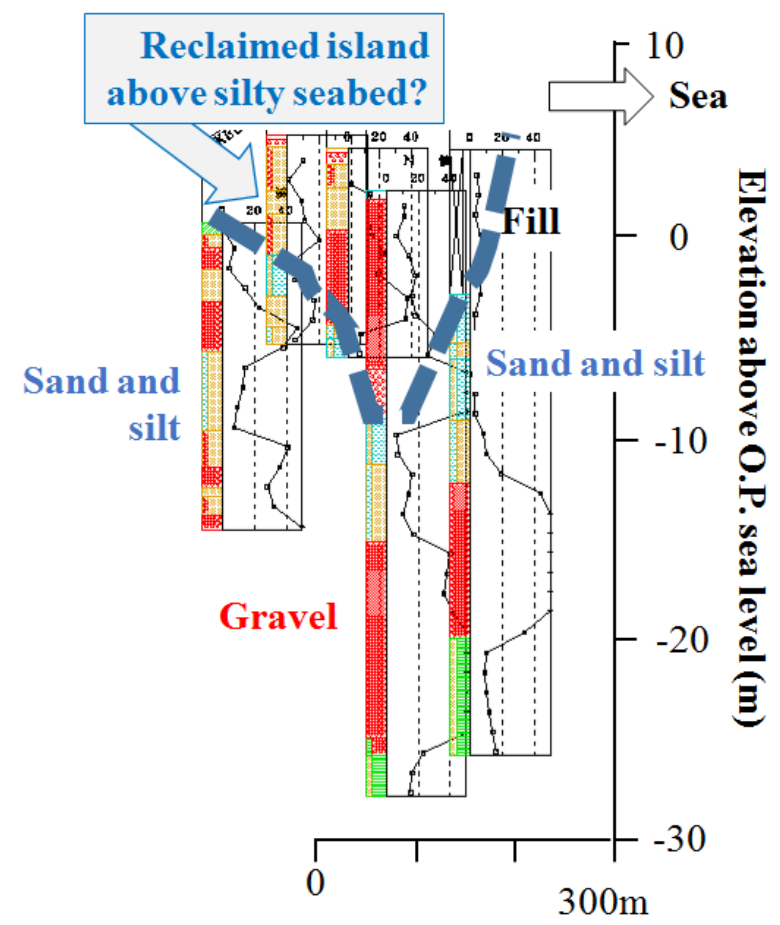

Fig. 9 Geological cross section of probable site of Kyo-gaShima Island in Kobe

It is further interesting that Fig. 10 illustrates the horizontal cross section of the studied area at $4 \mathrm{~m}$ below the sea level. The area that is considered to be the former island consists of a gravelly deposit, as stated 
above, while the area to the south and the west consists of silty/sandy material. Most probably this subsoil was a deposit of a channel that connected the outer sea and the ancient harbor.

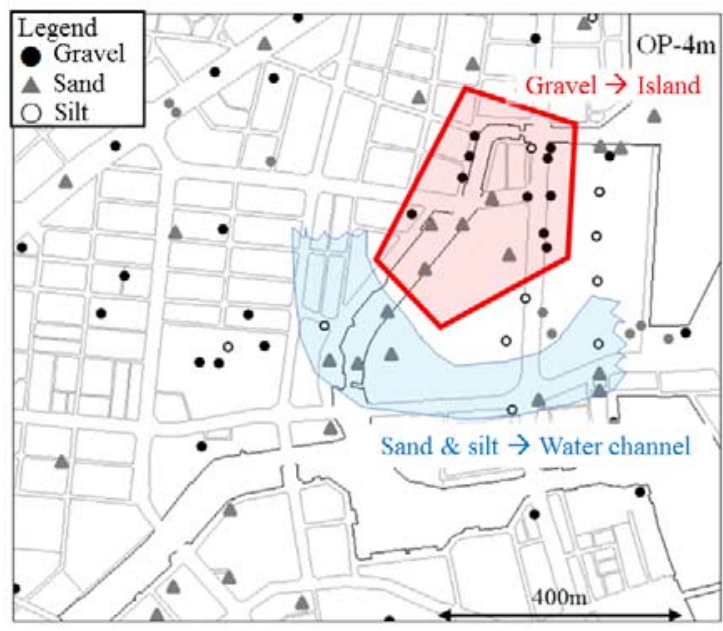

Fig. 10 Soil profile at $4 \mathrm{~m}$ below the sea level in the former Kyo-ga-Shima Island area.

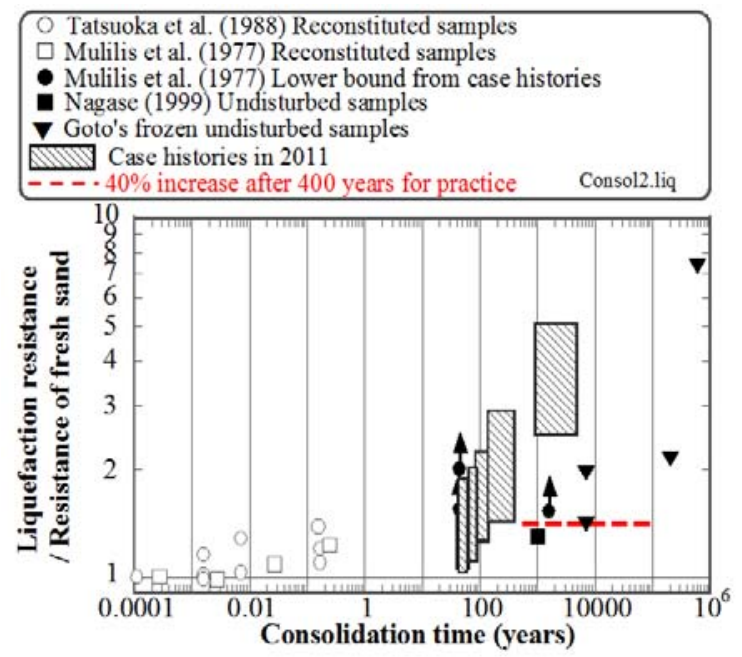

Fig. 11 Ageing effect on liquefaction resistance against time

The data from Tsukiji of Amagaski and Kyo-ga-Shima of Kobe are plotted in Fig. 8 as well. It seems that the boundary $F_{L}$ decreases with age significantly, although the range of boundary is still uncertain to some extent. Finally, $1 / \mathrm{F}_{\mathrm{L}}$ in the boundary area stands for the increase of liquefaction resistance with age. The increase of this value (1.0 in the youngest soil) was plotted in Fig. 11 against age. Although subject to variation, the obtained increase is still quantitative and consistent with the findings from laboratory tests (Tatsuoka et al., 1988) as well as field experiences (Mulilis et al., 1977, Nagase, 1999, and Goto in the present study). For practice, it is proposed that the liquefaction resistance should be increased by $40 \%$ from SPT-based calculation if soil is older than 400 years.

\section{6}

\section{CAUSATIVE MECHANISM OF AGEING}

As for the cause of engineering ageing of soil, Mitchell and Solymer (1984) and Kokusho et al. (2012) discussed the grain-to-grain cementation. In contrast, Wichtmann et al. (2005) and Kiyota et al. (2009) stated that sand grains can dislocate towards more stable packing under minor stress change or shaking. The present study is based on the second idea and attempted to validate it experimentally. Silica sand that was mixed with non-plastic fines to make $\mathrm{D}_{50}$ constant at $0.36 \mathrm{~mm}$ and vary the uniformity coefficient, $\mathrm{Uc}=1.5,4.0$ or 10 was deposited loosely in a container and was loaded under $25 \mathrm{kPa}$. Under this constant stress, microscopic photos were taken periodically from the horizontal direction through a transparent wall (Photo 1) in order to count the number of dislocation of grains.
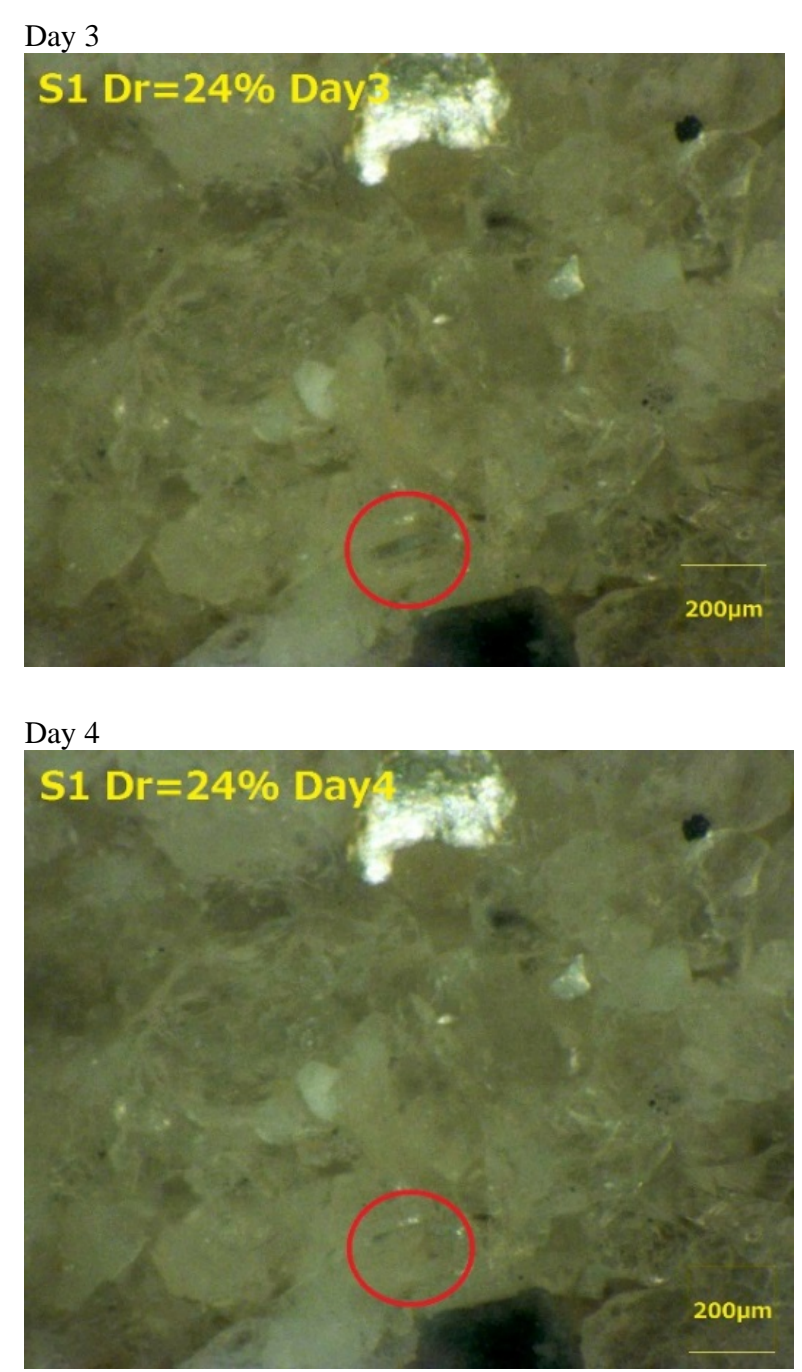

Photo 1 Particle movement in one-day time interval

Fig. 12 plots the accumulated number of grain dislocations during several weeks. It is shown that the greater Uc induces more dislocations. This finding is consistent with more increase of liquefaction resistance of well-graded sand over time as reported by 
Wakamatsu et al. (1992).

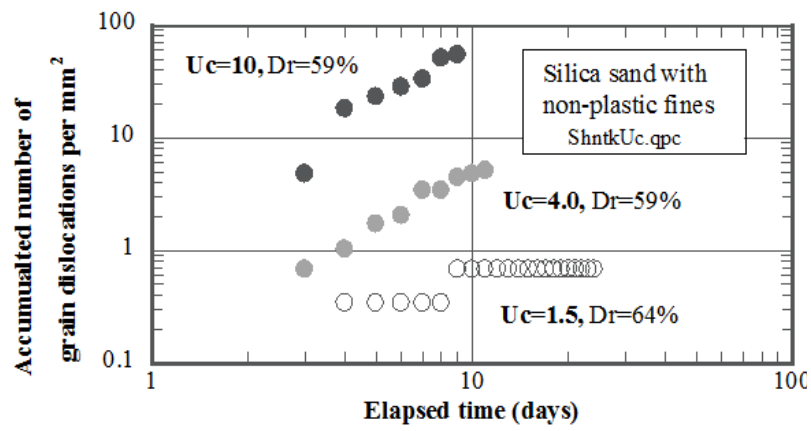

Fig. 12 Number of grain dislocations under different Uc

\section{CONCLUSIONS}

Experiences of liquefaction during past earthquakes were interpreted to shed light on the possible increase of liquefaction resistance with age. In spite of uncertainties, it was possible to quantitatively demonstrate the increase of liquefaction resistance with age. Hence, $40 \%$ increase after 400 years is reasonable for practice. This ageing study is helpful to improve the accuracy of liquefaction hazard mapping. Moreover, laboratory tests were conducted to show that grain dislocation is the possible cause of ageing.

\section{ACKNOWLEDGEMENTS}

Borehole data of Amagasaki and Kobe area was obtained from Kansai Geo-informatics Database. Earthquake motion was obtained from K-NET sites. Financial support was provided by Tokyo Gas Company. Those assistances are deeply appreciated by the authors.

\section{REFERENCES}

1) Baxter, C.D.P. and Mitchell, J.K. (2004) Experimental study on the aging of sands, J. Geotech. Geoenv. Eng. ASCE 130(10) 1051-1062.

2) Ishihara, K. and Yamazaki, F. (1980) Cyclic simple shear tests on saturated sand in multi-directional loading, Soil Found. 20(1) 45-59.

3) Kiyota, T., Koseki, J., Sato, T. and Kuwano, R. (2009) Aging effects on small strain shear moduli and liquefaction properties of in-situ frozen and reconstituted sandy soils, Soil Found. 49(2) 259-274.

4) Kusunoki, K., Nakazawa, H., Sugano, T. ,Okubo, Y., Kiku, H. and Fujita, D. (2013) Laboratory experiment on long-term recovery of liquefied ground state, Proc. JSCE(A1), 69(4) L326-L336 (in Japanese).

5) Lewis, M., Arango, I. and McHood, M. (2008) Site characterization philosophy and liquefaction evaluation of aged sands - A Savannah River site and Bechtel Perspective, Geotech Spec. Publ. 180, ASCE 540-558.

6) Massarsch, K.R. and Fellenius, B.H. (2002) Vibratory compaction of coarse-grained soils, Can. Geotech. J. 39(3) 695-709.
7) Matsuo, O. (2004) Simplified procedure for assessing liquefaction potential of soils in the specifications for highway bridges, Proc. JSCE 757(III-66) 1-20.

8) Mitchell, J.K. and Solymer, Z.V. (1984) Time-dependent strength gain in freshly deposited or densified sand, J. Geotech. Eng., ASCE, 110(11) 1559-1576.

9) Mulilis, J.P., Mori, K., Seed, H.B. and Chan, C.K. (1977) Resistance to liquefaction due to sustained pressure, J. Geotech. Eng., ASCE 103(7) 793-797.

10) Nagase, H., Shimizu, K., Hiro-oka, A., Mochinaga, S. and Ohta, M. (1999) Increase in liquefaction strength of sandy soils due to ageing, 34th JGS Ann. Conf. 987-998.

11) Sasaki, T. and Tanimoto, S. (2012) Liquefaction Resistant Design in Revised Highway Bridge Design Code, Found. Eng. Equip. 40(9) 55-59.

12) Schmertmann, J.H. (1991) The mechanical aging of soils, J. Geotech. Eng. ASCE 117(9) 1288-1330.

13) Seed, H.B. (1979) Soil liquefaction and cyclic mobility evaluation for level ground during earthquakes, Journal of Geotechnical Engineering, ASCE, 105(2) 201-255.

14) Seki, S., Mori, S. and Tachibana, H. (1992) Ageing effect in liquefaction resistance of sand by undisturbed sampling at archaeological site in Yuhigahama, Kamakura, 47th Annual Conv. JSCE, pp. 292-293 (in Japanese).

15) Tatsuoka, F., Iwasaki, T., Tokida, K., Yasuda, S., Hirose, M., Imai, T. and Kon-no, M. (1980) Standard penetration tests and soil liquefaction potential evaluation, Soil Found. 20(4) 95-111.

16) Tatsuoka, F., Kato, H., Kimura, M. and Pradhan, T. B. S. (1988) Liquefaction strength of sands subjected to sustained pressure, Soil Found. 28(1) 119-131.

17) Youd, T.L. and Hoose, S.N. (1977) Liquefaction susceptibility and geologic setting in dynamics of soil and soil structures, Proc, 6th WCEE 2189-2194.

18) Wakamatsu, K., Yasuda, S., Yoshida, N. and Yoshiwara, T. (1992) Liquefaction history of reclaimed land Part 3: Effects of aging on liquefaction resistance, 27th Ann Conv. JGS 1063-1066.

19) Wichtmann, T., Niemunis, A., Triantafyllidis, Th. and Poblete, M. (2005) Correlation of cyclic preloading with the liquefaction resistance, Soil Dynam. Earthq. Eng. 25 923-932. 